\title{
DYNAMICAL PROCESSES AT THE ICE-WATER INTERFACE DURING SOLIDIFIGATION
}

\author{
By J. H. Bilgram and H. Güttinger \\ (Laboratorium für Festkörperphysik, Eidg. Techische Hochschule Zürich, CH-8og3 \\ Zürich, Switzerland)
}

\begin{abstract}
Aвstract. The dynamics of the freezing process is studied at the surface of a growing ice crystal by means of Rayleigh spectroscopy. Light is scattered quasi-elastically at the interface. The line width is proportional to the square of the scattering vector. For a scattering angle of $90^{\circ}$ one measures about $2 \mathrm{krad} / \mathrm{s}$. The line width does not depend on the growth rate or thermal gradients at the interface. Light is scattered isotropically, which indicates that the correlation length is small compared with the wavelength of the scattered light. The intensity depends on the growth rate and shows a hysteresis in that dependence; at a minimum growth rate one observes the onset of fluctuations.

RÉsumé. Processus dynamiques a l'interface glace-eau pendant la solidification. Au moyen de la spectroscopie Rayleigh, on a étudié la dynamique des processus de gel à la surface d'un cristal de glace au cours de la croissance. La lumière est diffusée quasi-élastiquement à l'interface. La largeur de raie est proportionnelle à $k^{2}$ et, pour un angle de diffusion de $90^{\circ}$ vaut environ $2 \mathrm{krad} / \mathrm{s}$. La largeur de raie ne dépend pas de la vitesse de croissance ni des gradients thermiques de l'interface. La lumière est diffusée de manière isotrope; cela montre que la longueur de corrélation est petite comparée à la longueur d'onde de la lumière diffusée. L'intensité dépend de la vitesse de croissance et montre un hystérésis dans cette dépendance. Vers la vitesse de croissance minimale on observe l'apparition de fluctuations.
\end{abstract}

Zusammenfassung. Dynamische Prozesse an der Grenzfläche Eis-Wasser beim Erstarren. Mit Hilfe von Rayleighspektroskopie wird die Dynamik des Gefrierprozesses an der Oberfläche eines wachsenden Eiskristalls unter-
sucht. Licht wird an der Grenzfläche quasielastisch gestreut. Man misst eine Linienbreite, die proportional bum Quadrat des Streuvektors ist und bei einem Streuwinkel von $90^{\circ}$ etwa $2 \mathrm{krad} / \mathrm{s}$ beträgt. Die LinienGrenzfläche ab. Das Licht wird instumsgeschwindigkeit oder von einem thermischen Gradienten an der verglichen mit der Wellenlänge des gestreut. Das deutet darauf hin, dass die Korrelationslänge klein ist schwindigkeit ab und zeigt eine es gestreuten Lichtes. Die Intensität hängt von der Wachstumsgeminimalen Wachstumsgescheine Hysterese derart, dass man das Einsetzen der Fluktuationen bei einer

\section{InTRODUGtion}

In this paper the results of an experiment are reported which give information about the dynamics of the freezing process, which is an example of a first-order phase transition. Premelting and supercooling have been investigated in many laboratories. In these experiments bulk properties of the solid or of the liquid phase are studied at temperatures very near the phase transition. In the experiment described in this paper the solidification is studied at the interface by means of Rayleigh spectroscopy. This method has been chosen because potentially it can give information about the dynamics of fluctuations in a thin interface region. Through the choice of the scattering angle one selects a spatial Fourier component $\Lambda$ of the fluctuations. The lifetime of the Fourier components can be obtained from the analysis of the observed fluctuations of the intensity of the scattered light. In the range $200 \mathrm{~nm}<\Lambda<2$ ooo nm the experiment yields lifetimes of the order of magnitude of a millisecond, corresponding to a line width $\Gamma$ of a kiloradian per second. A block scheme of the system used is shown in Figure I. The liquid-solid interface is illuminated by a laser beam at grazing incidence. The quasi-elastically scattered light is detected by a photomultiplier. From the photon count statistics the correlation function of the intensity fluctuations is calculated by a digital correlator. It can be fitted by a single exponential with a decay time $\tau$. In the case of selfbeating spectroscopy, the line width $\Gamma$ of the scattered light is related to $\tau$ by the equation $2 \Gamma=I / \tau$. For details about this technique see Benedek ([ ${ }^{c}$ I 968$\left.]\right)$ and Chu (I974).

The ice-water system has been chosen for these investigations for the following reasons: (a) the technique for growing large pure ice single crystals has been previously developed in our laboratory, and (b) the absorption of the $488 \mathrm{~nm}$ radiation of an Argon ion laser is weak. The experimental conditions are far away from thermal equilibrium. 


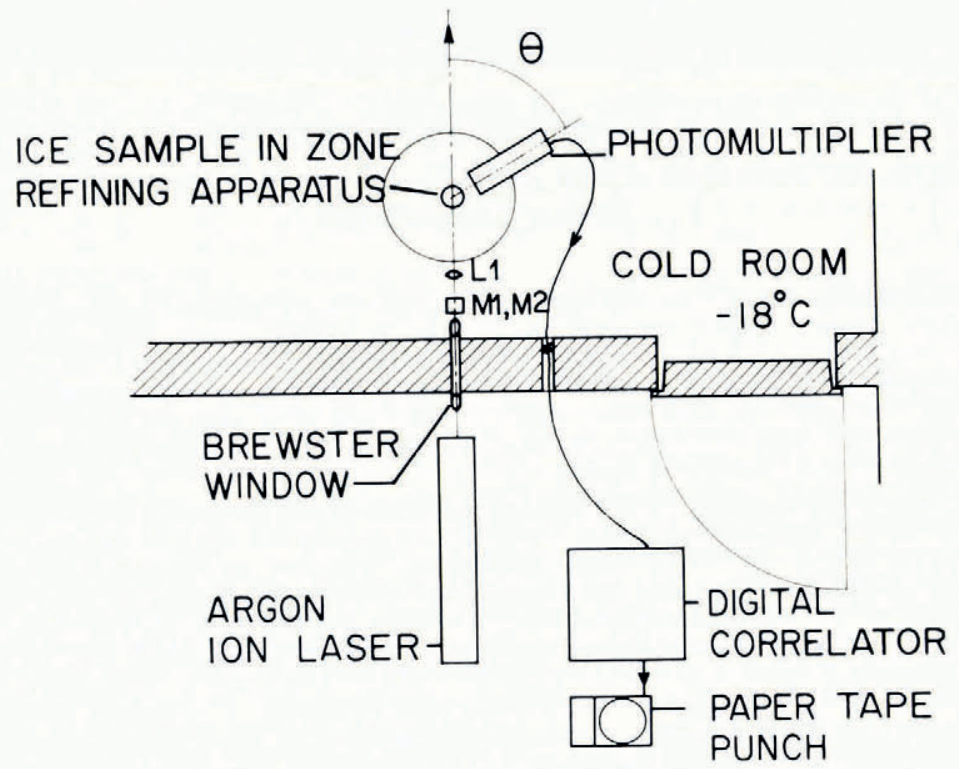

Fig. I. Pictorial representation of the self-beating technique.

\section{The ICE-WAter INTERface}

After some attempts with deionization and filtering systems, a zone-refining technique was finally adapted for the preparation of pure and dust-free water. This method is very efficient at producing high-purity crystals with low dislocation density (Bilgram and others, 1975).

A crystal is grown in an acryl glass tube on a seed whose $c$-axis is oriented parallel to the tube. The starting material is deionized water with a conductivity of $\sigma_{20}=6 \times \mathrm{ro}^{-8}$ $\Omega^{-1} \mathrm{~cm}^{-1}$. After about 15 zone-refining passes at a growth rate of $2 \mathrm{~cm} / \mathrm{d}$ the water is so pure that the Rayleigh intensity is as weak as the Raman intensity. A blue laser beam passing through the molten zone appears to be reddish. Dust particles cannot be detected. The dirty end is replaced by pure water after each pass. The light-scattering experiment is done in situ during a zone-refining cycle. This has the advantage that contamination of the solid or the liquid is prevented. The zone-refining apparatus as shown in Figure 2 is placed in a cold room at $-18^{\circ} \mathrm{C}$. An ice single crystal with a diameter of $36 \mathrm{~mm}$ is lowered through a heated zone into the cold bath. Measurements have been done at growth rates between $0.03 \mu \mathrm{m} / \mathrm{s}$ and $2.5 \mu \mathrm{m} / \mathrm{s}$. The temperature distribution in the heated zone is regulated by means of two thermostats to obtain a convex interface. The light beam is adjusted to pass the interface nearly parallel to the basal plane. The crystal is lowered into the cold bath exactly at the growth rate, thus the interface is always at the same position relative to the photomultiplier and the laser beam. The experiment is started by melting a zone in the region of highest purity in the zone-refined crystal. The growth process is initiated by lowering the crystal into the cooling bath. After some hours a basal plane is formed at the top of the lower crystal. If the basal plane is perfect, no defects that scatter light are created during the whole experiment. If there is a small-angle grain boundary crossing the basal plane no light scattering can be observed in this region. The diameter of the basal plane increases up to about $50 \%$ of the crystal diameter during an experiment at high growth rates. To prevent convection in the molten zone, the temperatures of the two heating thermostats must not exceed $4{ }^{\circ} \mathrm{C}$. Hence at high growth rates it is not possible to melt as much ice on top of the zone as water is frozen at 
the cold end. Therefore the gap between the solid phases closes during the experiment, limiting its duration to 2 to $5 \mathrm{~h}$. Complete freezing of the zone leads to destruction of the growth vessel.

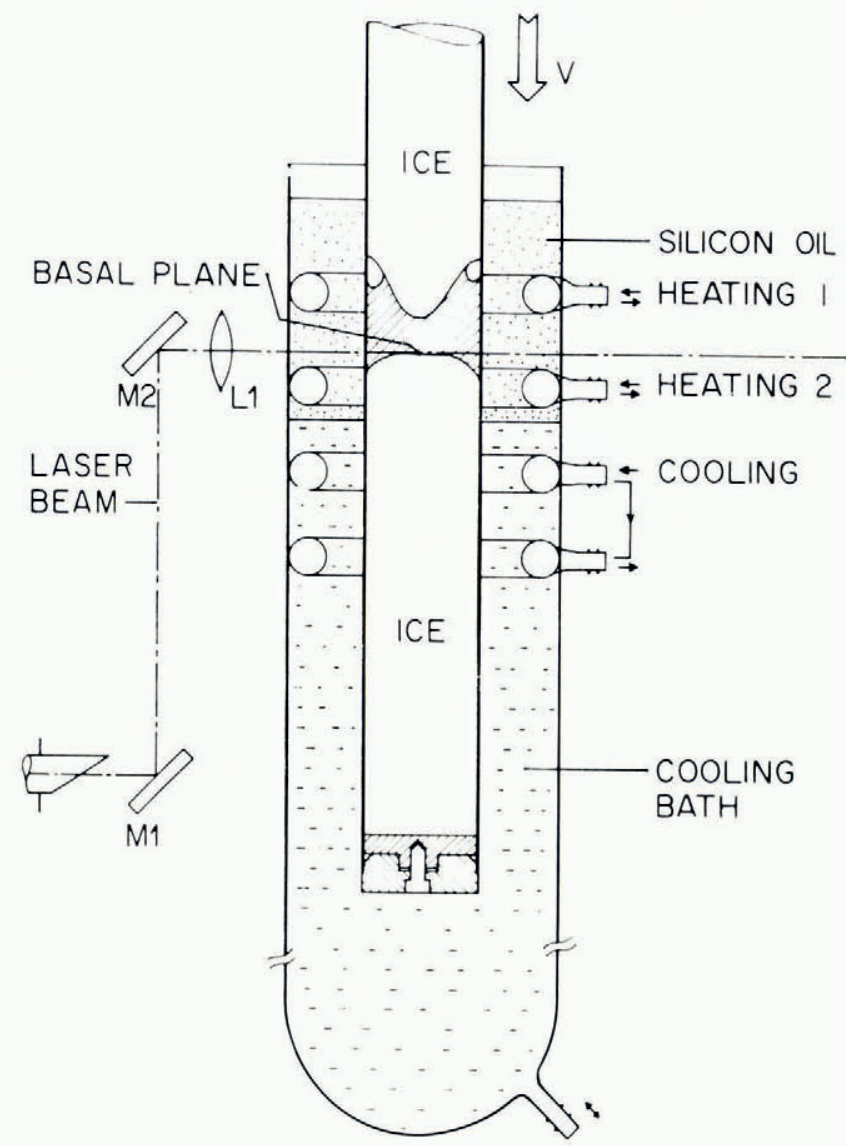

Fig. 2. Zone-refining apparatus in a cold room at $-18^{\circ} \mathrm{C}$.

\section{Experimental Results}

\section{I. Scattering power at the interface}

At the beginning of an experiment at low growth rates, no light is scattered at the interface, neither at the smooth basal plane nor at the rough part of the interface. If the growth rate exceeds a minimum value of about $v_{\min }=1.5 \mu \mathrm{m} / \mathrm{s}$, light scattering is observed at the basal plane. It starts at one point and spreads out over the whole plane. The scattering power increases with increasing growth rate as shown in Figure 3. It becomes weaker with decreasing growth rate but does not vanish at $v_{\min }$. Scattering seems to disappear at $v=0$. The lowest growth rate where scattering has been observed is $0.03 \mu \mathrm{m} / \mathrm{s}$. After melting the crystal surface, no scattering can be observed until the growth rate has again exceeded $v_{\min }$. Light scattering has been observed at the basal plane only. The strong blue line of an argon ion laser is used. The absorption of water has a minimum near this wavelength. The scattered intensity is proportional to the intensity of the incident beam up to a laser power of at least $400 \mathrm{~mW}$ as 


\section{( QUALITATIVE)}

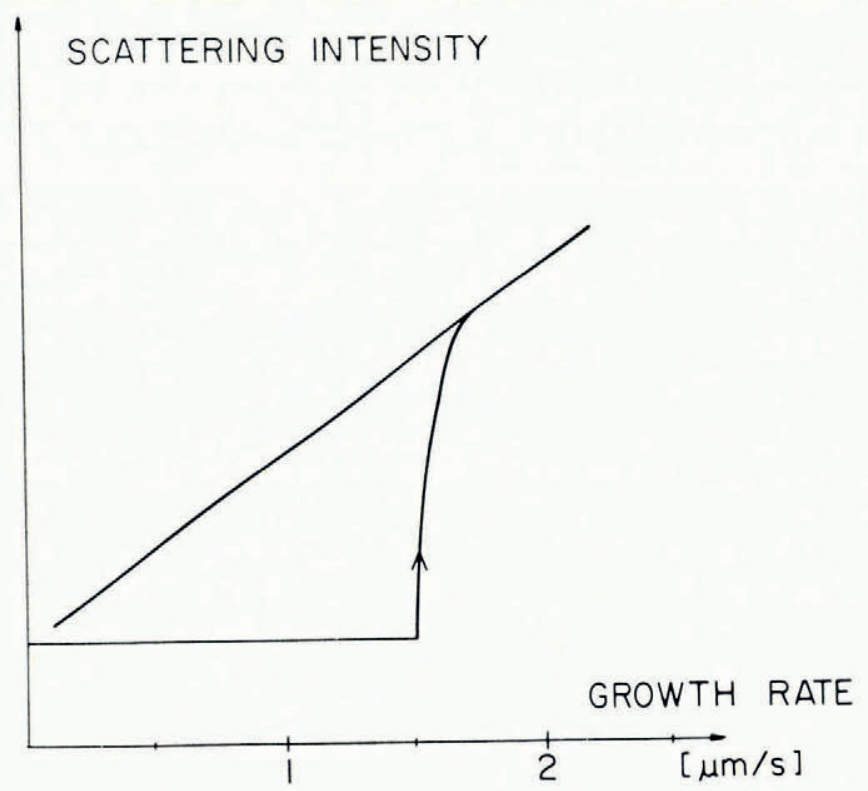

Fig. 3. Scattering power at the interface versus the growth rate. The lower branch of the hysteresis is observed after each melting of the interface only.

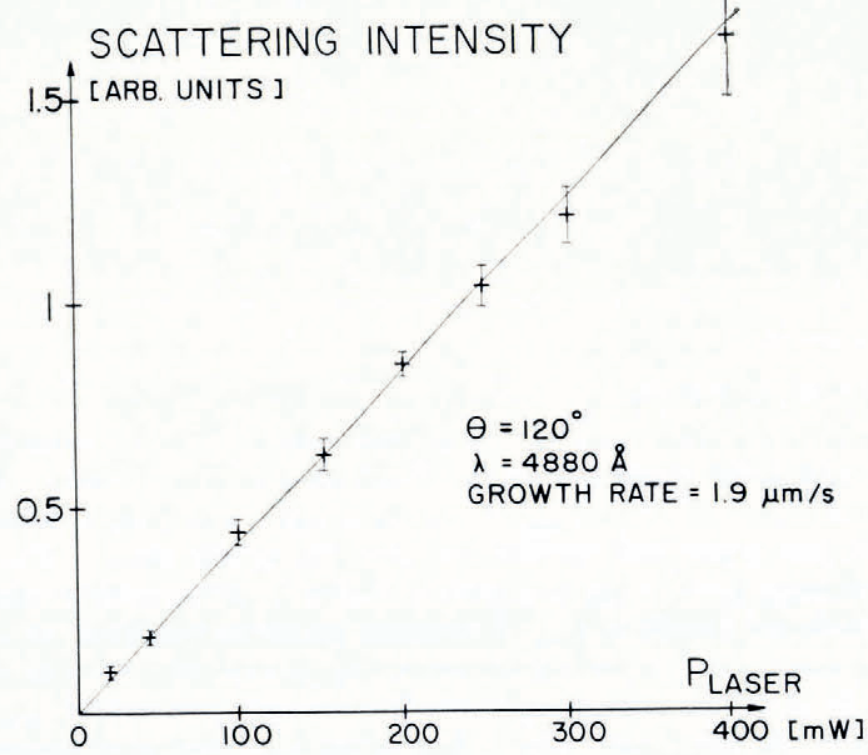

Fig. 4. Scattering intensity of the interface versus the power of the incident laser beam. 
shown in Figure 4, indicating that heating due to the laser beam does not significantly affect the scatterers. The angular dependence of the scattered intensity indicates that the light is scattered isotropically. Neither bulk water nor bulk ice scatter light with a comparable
intensity.

\subsection{Line width of the scattered light}

An example of a photon-count correlation function is shown in Figure 5. It can be fitted by a single exponential. A computer program performs a non-linear least-squares fit to the data (Bevington, [ $\left.\left.{ }^{\mathrm{c}} \mathrm{I} 969\right]\right)$. The line widths obtained from such correlation functions are plotted in Figure 6 versus the square of the scattering vector $K=(4 \pi n / \lambda) \sin ^{2}(\theta / 2)$. Two sets of data were used in this plot. They have been obtained at two different growth rates,

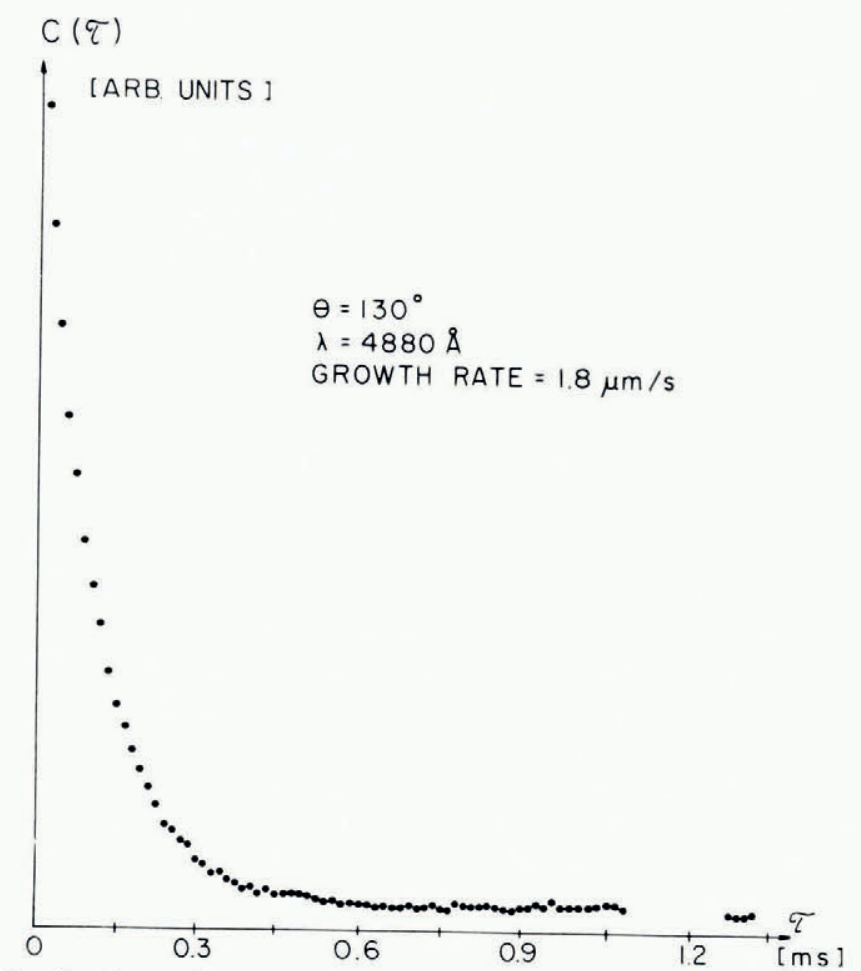

Fig. 5. Correlation function as obtained from the correlator for $\theta=140^{\circ}, \lambda=4880 A$, and $v=1.8 \mu \mathrm{m} / \mathrm{s}$.

$v_{1} \approx 0.2 \mu \mathrm{m} / \mathrm{s}$ and $v_{2}=\mathrm{r} .6 \mu \mathrm{m} / \mathrm{s}$. For both velocities the same linear dependence of $\Gamma$ on $K^{2}$ is found. The slope $\Gamma / K^{2}$ can be interpreted as a diffusion constant. The value obtained is $D=0.4 \times \mathrm{IO}^{-7} \mathrm{~cm}^{2} / \mathrm{s}$. In Figure 7 the line width is plotted versus the growth rate. No dependence is found. Reproducible results can only be obtained with very pure crystals.

\section{Discussion}

There are fluctuating inhomogeneities in the index of refraction in the solid-liquid interface region. The amplitude of the scattered light is proportional to the amplitude of the fluctuation. Its time dependence leads to the line broadening of the scattered light.

There are two experimental facts which give information about the nature of the fluctuations: (i) Within the precision of our experiment the decay of the correlation function can be 


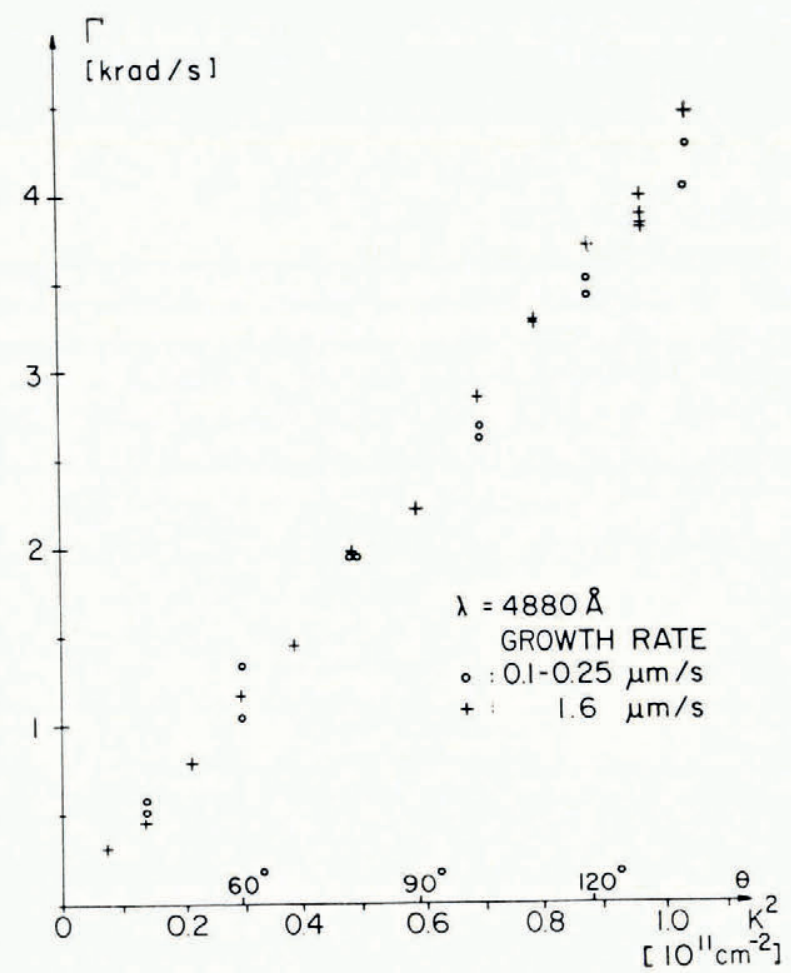

Fig. 6. Line width of the light scattered at the interface versus the square of the scattering vector.

fitted by a single exponential. (ii) The line width of the scattered light is proportional to the square of the scattering vector. From these facts we conclude, that the decay rate of the fluctuations is proportional to their amplitude. The spatial Fourier components of the fluctuations decay independently from each other.

In addition we know that the onset of the fluctuations is linked with a minimum growth rate. An interpretation for the intensity hysteresis will not be given in this paper. Although a nucleation process leads to a hysteresis behavior it is not an explanation because it seems to be inconsistent with the relation $\Gamma \propto K^{2}$ found in the experiment.

Two different models for an explanation will be considered: (I) free clusters exist in a region near to the phase boundary, or (II) there is a fluctuating interface. In both models we can distinguish between (A) moving disturbances, and (B) growing and decaying disturbances. (A) as well as (B) gives rise to a line-broadening, however only the cases (IA) and (IIB) lead to a $\Gamma \propto K^{2}$ dependence (Mullins, 1959). Therefore we only discuss these cases.

(IA) From the diffusion constant $D=4 \times 10^{-8} \mathrm{~cm}^{2} / \mathrm{s}$ measured in the experiment, a cluster diameter of $500 \AA$ can be calculated by using the Stokes-Einstein equation. Moreover, it is unlikely that their size distribution would lead to a decay describable by a simple exponential. Thus model (IA) is ruled out and only (IIB) remains.

(IIB) The decay of disturbances at the interface can occur by melting, surface diffusion, volume diffusion or by viscous flow. All these decay processes lead to a decay time which depends on the spatial wavelength of the disturbance, but only the melting process leads to a $\Gamma \propto K^{2}$ dependence (Mullins, 1959). This case will be discussed in more detail now.

The basic assumption is a linear dependence of the growth rate $v$ on the supercooling $\delta T$ (no nucleation processes). 


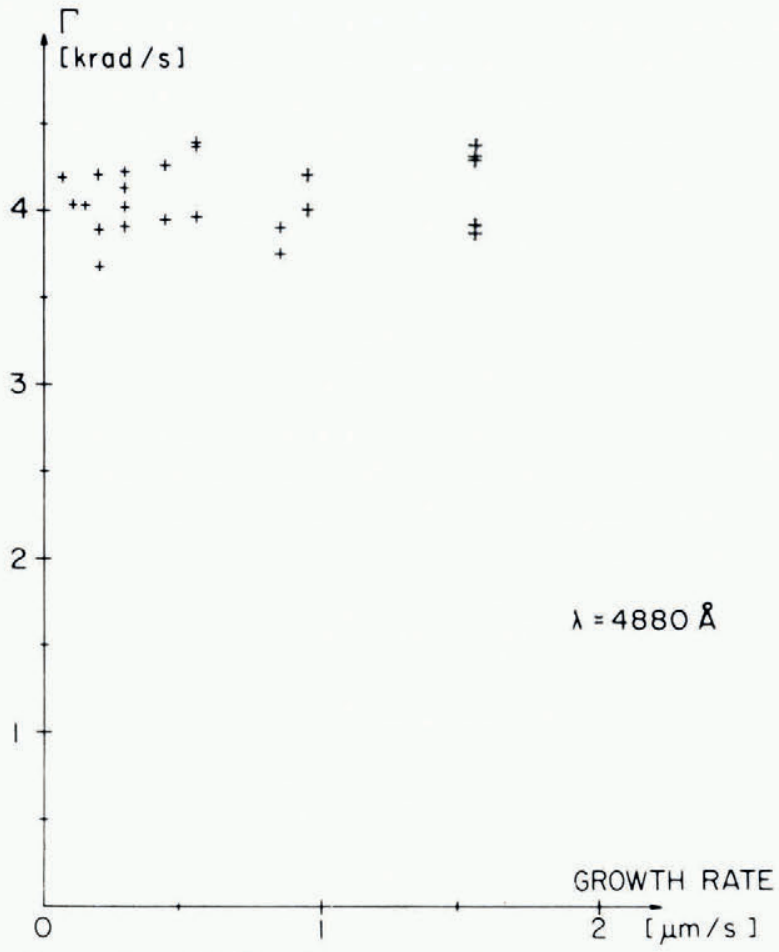

Fig. 7. Line width $\Gamma$ at $\theta=140^{\circ}$ as a function of the growth rate.

$$
v=\frac{\partial v}{\partial \delta T} \delta T ; \quad \frac{\partial v}{\partial \delta T}=\text { const. }
$$

In the experiment the change of the amplitude $A$ of an interface fluctuation on the basal plane is observed.

$$
\frac{\partial A}{\partial t}=\frac{\partial v}{\partial \delta T} \Delta T,
$$

where $\Delta T$ is an effective deviation of the temperature of an interface element from its equilibrium temperature with the melt given by

$$
\Delta T=T_{\mathrm{eq}}-T_{\mathrm{act}}-T_{\mathrm{c}},
$$

$T_{\text {eq }}$ being the equilibrium temperature of a flat interface-in the case of ice $T_{\mathrm{eq}}=0^{\circ} \mathrm{C}$, and $T_{\text {act }}$ the interface temperature which can be measured. The equilibrium temperature $T_{\mathrm{c}}$ of a curved interface differs from that of a flat interface. This difference can be calculated by means of the Gibbs-Thomson equation

$$
\tau_{\mathrm{c}}=\frac{\gamma_{\mathrm{SL}}}{S} \frac{\mathrm{d}^{2} A}{\mathrm{~d} x^{2}},
$$

where $\gamma_{\mathrm{SL}}$ is the surface tension and $S$ the melting entropy. $\mathrm{d}^{2} A / \mathrm{d} x^{2}$ is the curvature of the interface for amplitudes small compared to $\Lambda$. Considering one Fourier component of the disturbed interface

$$
A=A_{0} \sin \kappa x,
$$

the spatial wavelength $\Lambda$ is defined by the scattering vector $K=2 \pi / \Lambda$ selected in the experiment. 
The valleys of the disturbance will be filled up by freezing and the hills will melt.

The wavelength of the fluctuations which we observe in our experiment is so short that it is the curvature only that determines the kinetics of the interface disturbances; thermal and chemical gradients can be neglected. The mean supercooling which can be measured at the interface is also small compared to the contribution of the curvature:

$$
\left|T_{\text {eq }}-T_{\text {act }}\right| \ll\left|T_{\text {e }}\right|
$$

hence

$$
\Delta T=\frac{\gamma_{\mathrm{SL}}}{S} \frac{\mathrm{d}^{2} A}{\mathrm{~d} x^{2}}
$$

This is in agreement with the observation that there is no dependence of $\Gamma$ on thermal gradients. Therefore we do not need the detailed calculation of Corriell and Sekerka (1976) which includes thermal and chemical gradients. For the decay of the amplitude of a disturbance at the interface we obtain

$$
\frac{\partial A}{\partial t}=\frac{\partial v}{\partial \delta T} \frac{\gamma_{\mathrm{SL}}}{S} K^{2} A .
$$

The line width corresponding to the exponential decay is

$$
\Gamma=\frac{\mathrm{I}}{\tau}=\frac{\partial v}{\partial \delta T} \frac{\gamma_{\mathrm{SL}}}{S} K^{2} .
$$

The order of magnitude of $\partial v / \partial \delta T$ can be taken from experiments of other authors (Hillig, [ $\left.\left.{ }^{\mathrm{c}} \mathrm{I} 95^{8}\right]\right)$ :

$$
\frac{\partial v}{\partial \delta T} \approx 10^{-2} \mathrm{~cm} / \mathrm{s} \mathrm{K} .
$$

Using $\gamma_{\mathrm{SL}}=44 \mathrm{~mJ} / \mathrm{m}^{2}$ and $K^{2}$ (for $\left.\theta=90^{\circ}\right)=6 \times 10^{10} \mathrm{~cm}^{-2}$, one obtains $\Gamma=2.35 \mathrm{krad} / \mathrm{s}$.

The agreement of this number with the measured line width is astonishing and one is tempted to suspect that the above model describes what is going on at the interface after the onset of scattering. If this is correct we can conclude from the observed $K^{2}$ dependence of $\Gamma$ that (i) the growth rate of small fluctuations is proportional to the supercooling, and that (ii) the superposition principle is valid for heterophase fluctuations at the solid-liquid interface.

\section{Acknowledgements}

It is a pleasure to thank Professor W. Känzig for his encouragement of this work and numerous discussions. This work was supported by the Schweizerischer Nationalfonds zur Förderung der wissenschaftliche Forschung.

\section{REFERENCES}

Benedek, G. B. [ [ ${ }^{\mathrm{c}}$ I968.] Thermal fluctuations and the scattering of light. (In Chrétien, M., and others, ed. Statistical physics, phase transitions and superfluidity. Edited by M. Chrétien, E. P. Gross and S. Deser. Vol. 2. New York, etc., Gordon and Breach Science Publishers, p. I-98. (Brandeis University Summer Institute in Theoretical Physics, r966.))

Bevington, P. R. [ [ $\left.{ }^{\mathrm{c}} \mathrm{9} 69.\right]$ Data reduction and error analysis for the physical sciences. New York, etc., McGraw-Hill Book Co., Inc.

Bilgram, J. H., and others. 1975. Perfection of zone refined ice single crystals, [by] J. H. Bilgram and H. Wenzl and G. Mair. Fournal of Crystal Growth, Vol. 20, p. 319-21.

Chu, B. 1974. Laser light scattering. New York, Academic Press. (Quantum Electronics: Principles and Applications.) 
Coriell, S. R., and Sekerka, R. F. 1976. The effect of the anisotropy of surface tension and interface kinetics on morphological stability. Fournal of Crystal Growth, Vol. 34, p. 157-63.

Hillig, W. B. [ ${ }^{c} 195^{8}$.] The kinetics of freezing of ice in the direction perpendicular to the basal plane. (In Doremus, R. H., and others, ed. Growth and perfection of crystals: proceedings of an international conference on crystal growth held at Cooperstown, New York, on August 27-29, 1958. . . Edited by R. H. Doremus, B. W. Roberts and D. Turnbull. New York, John Wiley and Sons, Inc.; London, Chapman and Hall Ltd., p. 350-6o.) Mullins, W. W. r959. Flattening of nearly plane solid surface due to capillarity. Fournal of Applied Physics,
Vol. 30, No. I, p. 77-83.

\section{DISCUSSION}

W. В. КАмв: If the interpreted sinusoidal crenulation of the ice-water interface decays expotentially with time, with a time constant that you deduce, what causes this crenulation to form in the first place?

J. H. Bilgram: Figure 3 shows that light scattering starts when the system is far away from thermal equilibrium (minimum growth rate). As yet we do not have a quantitative interpretation for this onset of the fluctuations.

J. Hallett: Although the magnitude fluctuations produced by natural convection may be much greater than those observed here, it might be worth while doing the experiment upside down, then convective currents, if they did occur, would be quite different. An explanation in terms of a convective flow (with waves along the direction of flow) would give a possible explanation for the loss effect. How great is the horizontal temperature gradient in the liquid above the ice interface?

BilgRAm: It is not possible to reverse the growth direction in a zone-refining apparatus because of the density change during melting. We have done the experiment in a set-up similar to the Czochralski method. Here we have the other growth direction and the water is much more stable against convection. (Heating at the bottom of the growth vessel.) We have observed the same phenomena. The experimental data were not reproducible as it was impossible to get the system free from dust. The temperature gradients in the system are in the range $\mathrm{I}-\mathrm{IO} \mathrm{mm}$.

M. R. Bloch: Have you any indication of the survival time of these fluctuations?

BILGRAM: The order of magnitude is $\mathrm{IO}^{-3} \mathrm{~s}$.

C. JACGARD: Considering the large difference between the densities of ice and of water, could the observed fluctuations be due to density "waves" near the interface?

BILGRAM: One of the things which are not easy to understand in this experiment is the transport of heat away from the interface. It might be that density "waves" can help there. 